\title{
Infection Components of Wild-Type and Mutant Strains of Colletotrichum gloeosporioides f. sp. aeschynomene on Northern Jointvetch
}

\author{
Y. Luo, Research Associate, and D. O. TeBeest, Professor, Department of Plant Pathology, University of Arkansas, \\ Fayetteville 72701
}

\begin{abstract}
Luo, Y., and TeBeest, D. O. 1997. Infection components of wild-type and mutant strains of Colletotrichum gloeosporioides f. sp. aeschynomene on northern jointvetch. Plant Dis. 81:404409 .

Colletotrichum gloeosporioides f. sp. aeschynomene causes an anthracnose of northern jointvetch, Aeschynomene virginica. Infection components, including lesion number, latent period, lesion expansion rate, and sporulation, were measured in experiments conducted in controlled environments. Two wild-type strains (3-1-3 and CLA 5A), four benomyl-resistant strains (B13, B15, B18 and B21), and four nitrate nonutilizing mutant strains (Nit A, Nit R, Nit L, and Nit T) of the pathogen were tested. Nitrate nonutilizing strains caused significantly fewer lesions on northern jointvetch than did wild-type and benomyl-resistant strains. Latent periods were significantly shorter for the wild-type strain CLA 5A than for most other strains. Lesion expansion rates of all benomyl-resistant strains were significantly slower than those of the wildtype strains. Large variations in sporulation were observed for most strains, and no differences in sporulation were found between wild-type and mutant strains. The usefulness of infection component analysis for the identification of competitiveness of strains of fungal pathogens for biological control of weeds is discussed.
\end{abstract}

Additional keyword: Collego

The fungus Colletotrichum gloeosporioides (Penz.) Penz. \& Sacc. in Penz. f. sp. aeschynomene causes an anthracnose of northern jointvetch, Aeschynomene virginica (L.) B. S. P., a leguminous weed in rice and soybean fields. This pathogen was used as a commercial mycoherbicide, Collego, to control northern jointvetch in rice and soybean fields from 1982 to 1992 (3). The pathogenicity of C. gloeosporioides $\mathrm{f}$. sp. aeschynomene, and the infection processes, dispersal, competition between strains, and ecology of northern jointvetch anthracnose have been studied to better understand the weed pathosystem (21-24). These studies show that $C$. gloeosporioides f. sp. aeschynomene does not survive in soil or irrigation water, survives at low levels in plant refuse, and infects northern

Corresponding author: D. O. TeBeest

E-mail: dtebeest@comp.uark.edu

Current address of Y. Luo: Department of Plant and Soil Science, Southern Illinois University, Carbondale, IL 62901-4415.

Published with the approval of the Director of the Arkansas Agricultural Experiment Station, manuscript no. 94110 .

Supported in part by USDA grant no. 92-341957162.

Accepted for publication 22 January 1997.

Publication no. D-1997-0224-07R

(C) 1997 The American Phytopathological Society jointvetch plants over a wide range of environmental conditions $(21,23)$. These studies also show that the fungus is dispersed by wind-driven rain, insects, and treefrogs $(25,26,28)$.

Benomyl-resistant and nitrate nonutilizing strains of many fungi have been used in field and greenhouse experiments to study various aspects of pathogenesis and epidemiology $(2,5,6,9,13,16,17,20)$. Recently, Yang and TeBeest (27) reported that benomyl-resistant and nitrate nonutilizing strains of C. gloeosporioides f. sp. aeschynomene were not competitive with a wildtype strain in greenhouse studies. In repeated tests, whenever wild-type and mutant strains were coinoculated on northern jointvetch plants, a wild-type strain consistently became dominant in the population. The mechanisms leading to the population changes in these tests were not explained. Recently, Holmstruck-Ruddick and Mortenson (7) showed that benomylresistant strains of $C$. gloeosporioides $\mathrm{f}$. sp. malvae were less virulent than a wild-type strain, causing fewer but normal-sized lesions.

Infection of plants by a fungal pathogen is an expression of the combination of infection components, including infection efficiency, latent period, lesion expansion, infectiousness, and sporulation. Measuring and comparing infection components may be important in understanding the disease and predicting the survival, population dynamics, and competition of wild-type and mutant strains in the field.
The objectives of this study were to measure and compare the infection components of wild-type and mutant strains of $C$. gloeosporioides f. sp. aeschynomene on northern jointvetch and to determine the competitiveness of wild-type, fungicide-resistant, and nitrate nonutilizing mutant strains.

\section{MATERIALS AND METHODS}

Four infection components- the number of lesions per plant (infection efficiency), latent period, rate of lesion expansion, and sporulation-were measured for each of 10 strains of C. gloeosporioides f. sp. aeschynomene in two separate experiments.

Description of strains of the pathogen. Ten strains of $C$. gloeosporioides f. sp. aeschynomene were used in the experiments: two wild-type strains (3-1-3 and CLA 5A), four benomyl-resistant strains (B13, B15, B18, and B21) generated by ethyl methanesulfonate mutagenesis of strain 3-1-3 of C. gloeosporioides f. sp. aeschynomene (22), and four nitrate nonutilizing strains (Nit A, Nit L, Nit R, and Nit $T$ ), generated from strain $3-1-3$ by chlorate mutagenesis (4). All strains were cultured on Torula agar medium (21). Spore suspensions of approximately $10^{5}$ spores per $\mathrm{ml}$ were used for inoculation. All strains are preserved in cryostorage at the University of Arkansas in the Department of Plant Pathology.

Plants. Seeds of northern jointvetch were germinated on moistened filter paper in petri dishes at $28^{\circ} \mathrm{C}$ for $24 \mathrm{~h}$. Five fully germinated seeds were planted in $10-\mathrm{cm}$ diameter plastic pots in vermiculite, then thinned to three plants after emergence. Plants were grown in growth chambers (Model E7 Conviron, Controlled Environments, Asheville, NC) at $28^{\circ} \mathrm{C}$ with a $12-\mathrm{h}$ photoperiod. Plants were watered once daily and fertilized once biweekly with a solution of Peter's fertilizer (20:20:20 for N/P/K; Grace-Sierra Horticultural Products, Milpitas, CA).

Inoculation. Five-week-old plants were inoculated uniformly with each strain by spraying 30 plants with $20 \mathrm{ml}$ of a spore suspension. Plants were incubated in dew chambers at $28^{\circ} \mathrm{C}$ for $24 \mathrm{~h}$, then moved to growth chambers at $28^{\circ} \mathrm{C}$ for incubation and disease assessment.

Number of lesions. New lesions on the stem of each plant for each strain were counted daily, and the total number of lesions from the beginning to the end of latent period was determined. The average 
number of lesions per plant was computed for each strain.

Latent period. Beginning 3 days after inoculation, all newly visible lesions were marked with a pen and counted each day until 8 days after inoculation. The average latent period in days was calculated based on the following equation: $P=\Sigma_{3}^{8}\left(t_{\mathrm{i}} \times L_{\mathrm{i}}\right) /$ $\Sigma_{3}^{8} L_{\mathrm{i}}, i=3$, where $P$ is the average latent period in days, $L_{\mathrm{i}}$ is the number of new lesions that appeared on the $i$ th day after inoculation, and $t_{\mathrm{i}}$ is the $i$ th day $(3 \leq i \leq 8)$.

The cumulative frequency of new lesions versus latent period in days was calculated for each strain with the FREQ procedure of SAS (SAS Institute Inc., Cary, NC).

Lesion expansion rate. Ten lesions for each strain were arbitrarily selected and marked on stems 7 days after inoculation. The edges of each expanding lesion were re-marked each day for each strain. The total lesion area $\left(\mathrm{mm}^{2}\right)$ was determined by placing plastic coordinate paper $\left(1 \mathrm{~mm}^{2}\right.$ per square) over a lesion, and the total number of unit squares for each lesion was counted. Lesions were measured on days 11, 14, and 17 after inoculation. The lesion expansion rate $\left(L E R, \mathrm{~mm}^{2}\right.$ per day) of each lesion for each strain was calculated as the increase in lesion area between time intervals as follows: $L E R=\left(A_{2}-A_{1}\right) /\left(T_{2}-T_{1}\right)$, where $A_{1}$ and $A_{2}$ are lesion areas at time 1 $\left(T_{1}\right)$ and time $2\left(T_{2}\right)$ in days, respectively. The average $L E R$ for each strain was calculated from all sampled lesions.

Sporulation. Seven lesions for each strain were sampled 12 days after inoculation. Lesions were cut from the stems, washed with water, and incubated on moistened filter paper in petri dishes at $28^{\circ} \mathrm{C}$ in a dew chamber for $24 \mathrm{~h}$. The stem pieces were placed in a test tube with $2 \mathrm{ml}$ of water, and spores were dislodged by shaking for $2 \mathrm{~min}$ on a vortex mixer. The number of spores in the suspensions was determined with a hemacytometer as an average from 10 fields. The area of each lesion was measured by the method described above. The average number of spores per square millimeter of lesion was calculated for each lesion by dividing the number of spores in $2 \mathrm{ml}$ of spore suspension by the lesion area.
Data analysis. Analysis of variance (ANOVA) of the experimental data (randomized complete block design) was used to determine significant contributions to variances from strains, experiments, and their interactions. The ANOVA procedure of SAS was used on each infection component. Data from two experiments for each strain and infection component were combined for further analysis whenever experiments were not significantly different. The pair-wise differences between the means of any two strains for each infection component were determined by the least significant difference option of SAS. To compare wild-type with benomyl-resistant and nitrate nonutilizing strains, data of all four benomyl-resistant strains and of all four nitrate nonutilizing strains were combined, for each infection component. Thus, the combined data contained the wild-type strains, the benomyl-resistant strains, and the nitrate nonutilizing strains. The comparisons of wild-type strains with benomyl-resistant and with nitrate nonutilizing strains were made with the Tukey option of SAS to analyze the difference among means and strains in the data set of unequal sample size.

\section{RESULTS}

The results described below are comparisons of the infection components of a single parental strain, 3-1-3, and four isolates of two separate types of mutants, benomyl-resistant and nitrate nonutilizing strains, derived from that parental strain. The data were obtained from replicated experiments conducted in controlled environments.

Number of lesions. Results of ANOVA for this component (Table 1) demonstrate that strains of $C$. gloeosporioides $\mathrm{f}$. $\mathrm{sp}$. aeschynomene contributed significant variance to the total variance while the variances caused by experiments and the interaction between strains and experiments were not significant. Thus, the results of the two experiments were combined for further analysis. The means calculated from two experiments for each strain and the corresponding standard deviations were also used to compare strains (Table 2).

The average number of lesions caused

Table 1. Results of analysis of variance (ANOVA) in number of lesions, latent period, lesion expansion rate, and sporulation for 10 strains of Colletotrichum gloeosporiodes $\mathrm{f}$. sp. aeschynomene on northern jointvetch ${ }^{\mathrm{a}}$

\begin{tabular}{|c|c|c|c|c|c|c|c|c|c|}
\hline \multirow[b]{2}{*}{ Source } & \multirow[b]{2}{*}{ DF } & \multicolumn{2}{|c|}{ Number of lesions } & \multicolumn{2}{|c|}{ Latent period } & \multicolumn{2}{|c|}{$\begin{array}{c}\text { Lesion } \\
\text { expansion rate }\end{array}$} & \multicolumn{2}{|c|}{ Sporulation } \\
\hline & & $\begin{array}{l}\text { Mean } \\
\text { square }\end{array}$ & $P r>F$ & $\begin{array}{l}\text { Mean } \\
\text { square }\end{array}$ & $P r>F$ & $\begin{array}{l}\text { Mean } \\
\text { square }\end{array}$ & $P r>F$ & $\begin{array}{l}\text { Mean } \\
\text { square }\end{array}$ & $P r>F$ \\
\hline Strain & 9 & 215.9 & 0.0001 & 20.1 & 0.0001 & 179.9 & 0.0001 & $\begin{array}{r}1.075 \\
\times 10^{8}\end{array}$ & 0.0001 \\
\hline Experiment & 1 & 3.9 & 0.0995 & 0.8 & 0.2971 & 21.2 & 0.0179 & $\begin{array}{l}1.164 \\
\times 10^{8}\end{array}$ & 0.0247 \\
\hline $\begin{array}{l}\text { Strain } \times \\
\text { experiment }\end{array}$ & 9 & 0.3 & 0.9941 & 10.3 & 0.0001 & 0.3 & 0.9999 & $\begin{array}{l}2.397 \\
\times 10^{8}\end{array}$ & 0.0001 \\
\hline
\end{tabular}

a The ANOVA procedure of SAS (SAS Institute, Cary, NC) was used. by the two wild-type strains were significantly different from each other (Table 2). CLA 5A caused more lesions on northern jointvetch than did 3-1-3. When compared with wild-type strain CLA 5A, all nitrate nonutilizing strains and all benomyl-resistant strains except B18 caused significantly fewer lesions on northern jointvetch. No significant differences in this component among nitrate nonutilizing strains except Nit $T$ were found. Significant differences among benomyl-resistant strains were found. All benomyl-resistant strains caused significantly more lesions than did all nitrate nonutilizing strains.

Generally, all benomyl-resistant strains caused significantly more lesions than did $3-1-3$, and all nitrate nonutilizing strains caused significantly fewer lesions than did 3-1-3. Comparisons of two wild-type strains with two sets of mutant strains were made after combining the data of four benomyl-resistant strains and data of four nitrate nonutilizing strains, respectively. The means and standard deviations for this component were combined and used for further comparisons. The order of strains in terms of lesion number as an infection

Table 2. The mean number of lesions per plant caused by 10 strains of Colletotrichum gloeosporiodes f. sp. aeschynomene on northern jointvetch

\begin{tabular}{lll}
\hline Strain & Mean $^{\mathbf{y}}$ & SD \\
\hline 3-1-3 & $4.00 \mathrm{e}^{\mathrm{z}}$ & 1.74 \\
CLA 5A & $8.16 \mathrm{a}$ & 1.68 \\
B13 & $7.15 \mathrm{~b}$ & 1.21 \\
B15 & $5.57 \mathrm{~d}$ & 0.73 \\
B18 & $8.00 \mathrm{a}$ & 1.24 \\
B21 & $6.32 \mathrm{c}$ & 1.75 \\
Nit A & $1.78 \mathrm{~g}$ & 0.61 \\
Nit L & $1.88 \mathrm{~g}$ & 0.64 \\
Nit R & $1.77 \mathrm{~g}$ & 0.72 \\
Nit T & $2.83 \mathrm{f}$ & 1.04 \\
\hline
\end{tabular}

y The data are from two separate experiments.

$\mathrm{z}$ Values in a column followed by a letter in common are not significantly different $(P=$ 0.05 , least significant difference option of SAS).

Table 3. Mean latent period in days of 10 strains of Colletotrichum gloeosporiodes $\mathrm{f}$. sp. aeschynomene on nothern jointvetch

\begin{tabular}{lll}
\hline Strain & Mean $^{\mathbf{y}}$ & SD \\
\hline $3-1-3$ & $4.89 \mathrm{de}^{\mathrm{z}}$ & 0.84 \\
CLA 5A & $4.74 \mathrm{f}$ & 0.79 \\
B13 & $5.47 \mathrm{a}$ & 0.84 \\
B15 & $5.03 \mathrm{~cd}$ & 0.95 \\
B18 & $5.46 \mathrm{a}$ & 0.79 \\
B21 & $5.21 \mathrm{~b}$ & 1.02 \\
Nit A & $5.04 \mathrm{bcd}$ & 0.81 \\
Nit L & $5.08 \mathrm{bc}$ & 0.85 \\
Nit R & $5.24 \mathrm{~b}$ & 0.89 \\
Nit T & $4.82 \mathrm{ef}$ & 0.83 \\
\hline
\end{tabular}

$\mathrm{y}$ The data are from two separate experiments.

z Values in a column followed by a letter in common are not significantly different $(P=$ 0.05 , least significant difference option of SAS). 
component (at $P=0.05$, Tukey option) generally showed that CLA 5A caused more lesions than did benomyl-resistant strains, which caused more lesions than did 3-1-3, which, in turn, caused more lesions than did nitrate nonutilizing strains.

Latent period. The data demonstrated that strains contributed significantly to the variance of the latent period at $P=0.05$ (Table 3) while the variance caused by experiments was not significant between the two experiments. Also, interactions between strains and experiments were significant.

In general, the latent period of wild-type strain CLA 5A was shorter than those of all other tested strains (Tables 1 and 3). The average latent period for two wild-type strains was less than 5 days and that of all mutant strains was greater than 5 days except for Nit T. Latent periods for all benomyl-resistant strains, except B15, were significantly longer than the latent period of strain 3-1-3. However, only two of the four nitrate nonutilizing strains were different from 3-1-3 for length of the latent period (Table 4).

The latent period, measured as the development of visible lesions over time, was determined as the cumulative frequency of new lesions for each strain (Fig. 1). Comparisons of wild-type strains with benomyl-resistant strains (Fig. 1A) demonstrated that the proportion of lesions with shorter latent periods for wild-type strains was greater than that of benomyl-resistant

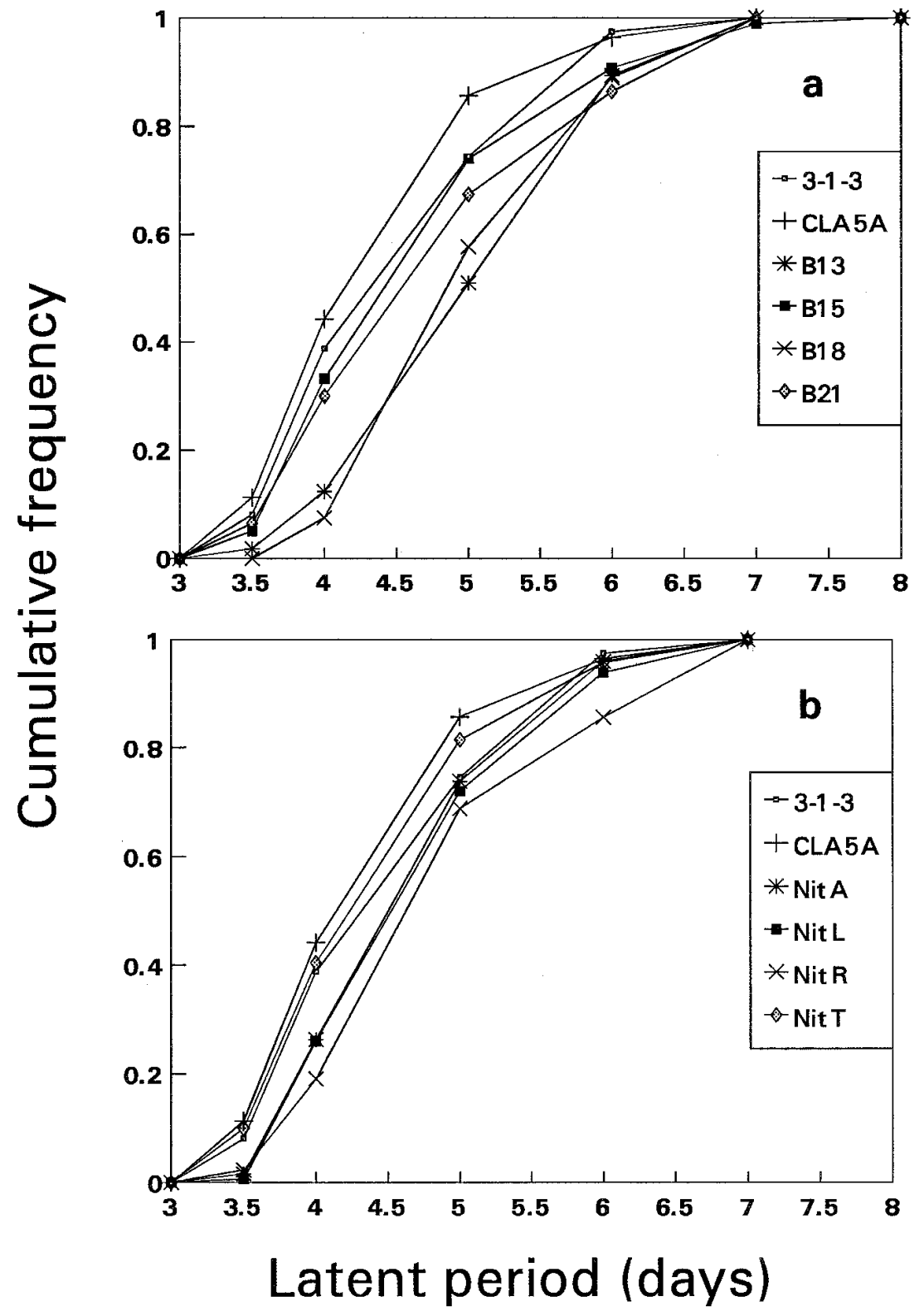

Fig. 1. Development of lesions on northern jointvetch as represented by cumulative frequency of the number of lesions appearing 3 to 8 days after inoculation with wild-type, benomyl-resistant, and nitrate nonutilizing strains of Colletotrichum gloeosporioides f. sp. aeschynomene. (A) Comparison between wild-type and benomyl-resistant strains. (B) Comparison between wild-type and nitrate nonutilizing strains. strains, especially for B13 and B18. For example, $40.2 \%$ (cumulative frequency $=$ 0.442) of the lesions for CLA 5A were visible by the fourth day while only $12.4 \%$ (cumulative frequency $=0.124$ ) of the lesions for $\mathrm{B} 13$ and $7.5 \%$ (cumulative frequency $=0.075$ ) of the lesions for B18 were visible at that time (Fig. 1A). Similar results were obtained for the comparisons of wild-type strains with nitrate nonutilizing strains (Fig. 1B). The proportion of lesions with shorter latent period for wildtype strains was greater than that for nitrate nonutilizing strains except for Nit $\mathrm{T}$.

Analysis of the combined data for benomyl-resistant and nitrate nonutilizing strains (Table 3) demonstrated that the latent period for CLA 5A was significantly shorter than that for 3-1-3 and mutant strains. No significant difference in this component between 3-1-3 and nitrate nonutilizing strains was found. Generally, the latent period for the wild-type strain CLA 5A was the shortest, the latent period for benomyl-resistant strains was the longest, and the latent periods for nitrate nonutilizing strains were intermediate in length.

LER. Strains of C. gloeosporioides f. sp. aeschynomene contributed significantly to the total variance of the LERs (Table 4). The results of the two experiments were not significantly different at $P=0.05$ and were combined for further analysis. The variance caused by the interaction between strains and experiments also was not significant (Tables 1 and 4). The average $L E R$ and standard deviations for each strain were used to determine differences between the strains for this component (Table 4). The two wild-type strains differed significantly from each other in this component (Table 4). The LER of 3-1-3 was significantly faster than that of all other strains. The $L E R$ for CLA 5A was not different from that for all nitrate nonutilizing strains except Nit A.

LERs for all benomyl-resistant strains were significantly slower than those for all

Table 4. The mean lesion expansion rates $\left(\mathrm{mm}^{2} /\right.$ day) for 10 strains of Colletotrichum gloeosporiodes $\mathrm{f}$. sp. aeschynomene on northern jointvetch

\begin{tabular}{lcc}
\hline Strain & Mean $^{\mathbf{y}}$ & SD \\
\hline 3-1-3 & $10.26 \mathrm{a}^{\mathrm{z}}$ & 0.91 \\
CLA 5A & $8.56 \mathrm{~b}$ & 1.05 \\
B13 & $0.86 \mathrm{e}$ & 0.83 \\
B15 & $2.45 \mathrm{~d}$ & 0.54 \\
B18 & $1.89 \mathrm{de}$ & 1.47 \\
B21 & $3.16 \mathrm{~cd}$ & 1.72 \\
Nit A & $4.27 \mathrm{c}$ & 1.64 \\
Nit L & $8.55 \mathrm{~b}$ & 2.50 \\
Nit R & $8.45 \mathrm{~b}$ & 4.07 \\
Nit T & $8.34 \mathrm{~b}$ & 1.43 \\
\hline
\end{tabular}

y The data are from two separate experiments.

${ }^{\mathrm{z}}$ Values in a column followed by a letter in common are not significantly different $(P=$ 0.05 , least significant difference option of SAS). 
other strains. Lesions caused by B13 expanded more slowly than those caused by all other benomyl-resistant strains. The LER of Nit A was significantly slower than those of other nitrate nonutilizing strains. Generally, the LERs for all nitrate nonutilizing strains were significantly faster than those for all benomyl-resistant strains except for Nit A.

Means and standard deviations for wildtype and mutant strains were calculated based on combined data for benomyl resistant and nitrate nonutilizing strains (Table 5). The results of comparisons using the Tukey procedure of SAS demonstrated that a single isolate, 3-1-3, constituted the fastest group, and CLA 5A and nitrate nonutilizing strains constituted a second group with an intermediate rate of increase. The benomyl-resistant strains constituted the third group, with the slowest rate of lesion growth (Table 5).

Sporulation. In these experiments, strains but not experiments contributed significantly to the total variance for sporulation (Table 6). However, variances caused by interactions between strains and experiments also were significant (Tables 1 and 6). In general, all strains could be placed in one of two groups, and a single strain, Nit R, was different from all other strains with a greater level of sporulation.

When data from the two experiments were combined into three groups, consisting of wild-type, benomyl-resistant, and nitrate nonutilizing isolates, respectively, the statistical analysis showed that sporulation for wild-type strains was not significantly different from that of most mutant strains although CLA 5A produced relatively more spores than did the other strains (Table 6). High standard deviations of the means were observed for some strains.

Table 5. Means and standard deviations for infection components for wild-type and mutant strains of Colletotrichum gloeosporiodes $\mathrm{f}$. sp. aeschynomene on northern jointvetch

\begin{tabular}{llcl}
\hline Component & Strain $^{\mathbf{x}}$ & Mean $^{\mathbf{y}}$ & SD \\
\hline Lesions per plant (no.) & $3-1-3$ & $4.00 \mathrm{c}^{\mathbf{z}}$ & 1.74 \\
& CLA 5A & $8.16 \mathrm{a}$ & 1.68 \\
& ben. & $6.75 \mathrm{~b}$ & 1.59 \\
& Nit & $2.07 \mathrm{~d}$ & 0.88 \\
Latent period (day) & 3-1-3 & $4.89 \mathrm{~b}$ & 0.84 \\
& CLA 5A & $4.73 \mathrm{c}$ & 0.79 \\
& ben. & $5.31 \mathrm{a}$ & 0.91 \\
& Nit & $5.02 \mathrm{~b}$ & 0.88 \\
Lesion expansion rate $\left(\mathrm{mm}^{2} /\right.$ day) & 3-1-3 & $10.26 \mathrm{a}$ & 0.91 \\
& CLA 5A & $8.56 \mathrm{~b}$ & 1.05 \\
& ben. & $2.09 \mathrm{c}$ & 1.54 \\
& Nit & $7.27 \mathrm{~b}$ & 3.26 \\
Sporulation (spores $/ \mathrm{mm}^{2}$ ) & 3-1-3 & $5,067 \mathrm{a}$ & 3,483 \\
& CLA 5A & $6,680 \mathrm{a}$ & 7,077 \\
& ben. & $4,297 \mathrm{a}$ & 6,600 \\
& Nit & $4,777 \mathrm{a}$ & 6,412 \\
\hline
\end{tabular}

$\overline{\mathrm{x}}$ ben. = benlate-resistant stains, Nit $=$ nitrate nonutilizing stains.

y Data are from two experiments for each strain and component.

z Means followed by a letter in common are not significantly different $(P=0.05$, Tukey option of SAS).

\section{USSION}

the fitness of a phenotype is its ability to reproduce relative to that of another phenotype. They introduced the application of life and reproductivity tables to estimate that general fitness of an isolate or strain of a pathogen may be estimated by analysis (29). Component foen used to evaluate host restance and several disease or infection conponts $(1,10,14,29)$, For fungal disdevelopment (expansion), infectious period, and sporulation (15).

In this study, we compared four infection components of 10 strains of C. gloeosporioides $\mathrm{f}$. $\mathrm{sp}$. aeschynomene in an effort to better understand factors that affected the competitiveness of individual strains. The general conclusion from this study is that benomyl-resistant and nitrate nonutilizing strains of $C$. gloeosporioides f. sp. aeschynomene are less competitive than -type strains because they are reduced in one or more of the infection comporesistant and nitrate nonutilizing strains. For instance, following inoculation with wild-type strains, about $40 \%$ of the lesions appeared within 4 days but only about $10 \%$ of the total number of lesions caused by B13 and B15 appeared within that period Similar results were found in the comparisons of wild-type strains with ninonutilizing strains. The amount of tesions for most strains was variable, and it was difficult to detect difbetween wild-type and mutant strains. The relationship between the number of spores produced per lesion and lethe fitness of a pathogen and further sugclude infection efficiency, latency, lesion sion size is unclear. However, we can estimate that the normal range of sporulation is approximately 2,000 to 6,000 spores per $\mathrm{mm}^{2}$ of lesion for this pathosystem. The total number of spores produced on lesions and the dispersal characteristics described for this pathosystem may determine, in part, not only how rapidly this disease develops on northern jointvetch but also how strains spread and compete for infection sites on healthy northern jointvetch plants. These results may further help explain the results of the competition tests between wild-type and benomyl-resistant and nitrate nonutilizing strains previously reported by Yang and TeBeest (27).

A similar study on the general fitness of wild-type and mutant strains of a fungal pathogen was conducted by Kadish and Cohen (8). They compared the general fitness of metalaxyl-sensitive and -resistant strains of Phytophthora infestans on potato plants and found that lesions caused by metalaxyl-resistant strains were significantly larger than those caused by metalaxyl-sensitive strains on untreated potato leaves (8). However, they found no significant differences among strains for sporulation and infection efficiency. Following analysis with a compound fitness index, they concluded that metalaxyl-resistant strains were significantly more fit than metalaxyl-sensitive strains on untreated potato tissues. Thus, analysis of infection components has been demonstrated as a feasible method to estimate the general fitness of strains of plant pathogens.

Infection components can be combined into one parameter to represent the integrated effects of components. Previous work on the integration of fitness components for some crop pathogens has been reported $(8,11,12,18,19,29)$. Shaner and Hess (19) constructed equations to help predict how various components of slowrusting resistance interacted on wheat under field conditions. These equations incorporated the effects of infection effi-

Table 6. Sporulation (as spores per $\mathrm{mm}^{2}$ of lesion surface) of 10 strains of Colletotrichum gloeosporiodes $\mathrm{f}$. sp. aeschynomene on lesions excised from northern jointvetch and incubated for $24 \mathrm{~h}$ at $28^{\circ} \mathrm{C}$

\begin{tabular}{lcr}
\hline Strain & Mean $^{\mathbf{y}}$ & \multicolumn{1}{c}{ SD } \\
\hline 3-1-3 & $5,067 \mathrm{bc}^{\mathrm{z}}$ & 3,483 \\
CLA 5A & $6,650 \mathrm{ab}$ & 7,077 \\
B13 & $8,467 \mathrm{a}$ & 11,933 \\
B15 & $2,070 \mathrm{c}$ & 2,668 \\
B18 & $3,027 \mathrm{c}$ & 2,789 \\
B21 & $3,871 \mathrm{bc}$ & 3,934 \\
Nit A & $3,140 \mathrm{c}$ & 3,493 \\
Nit L & $3,214 \mathrm{c}$ & 2,271 \\
Nit R & $10,061 \mathrm{a}$ & 11,416 \\
Nit T & $3,517 \mathrm{bc}$ & 2,558 \\
\hline
\end{tabular}

y The data are from two separate experiments.

${ }^{z}$ Values in a column followed by a letter in common are not significantly different $(P=$ 0.05 , least significant difference option of SAS). 
ciency, latent period, uredium size, urediospore production, and infectious period and were used to predict how certain combinations of slow-rusting resistance components might retard an epidemic. Shaner (18) also studied the importance of slowrusting resistance components to Puccinia recondita by simulations and suggested that a slow growth rate of uredinia would be a significant factor in retarding disease development in the field. Leonard and Mundt (11) analyzed the quantitative relationship between infection rate and disease resistance components in cereal rusts and mildews and constructed an equation in which latent period, infectious period, and reproduction capacity were combined to quantitatively describe the infection rate. Kadish and Cohen (8) used a compound fitness index to combine disease components of Phytophthora infestans into one value in terms of infection efficiency, lesion size, and sporulation. Luo and Zeng (12) used a simulation approach to compute the importance of each resistance component of wheat cultivars with partial resistance to $P$. striiformis, by which the integrated infection index was calculated.

Combinations of disease components may be a simple way to estimate overall fitness of a strain of the pathogen and its ability to cause disease. In this study, relative fitness value of each component for each strain, related to that of wild-type strain CLA 5A, was calculated. The following equation was used to calculate the relative value for a certain disease component (except for latent period) for a given strain: $R=M_{\mathrm{st}} / M_{\mathrm{CLA5A}}$, where $R$ is the relative value of a certain component for a given strain, $M_{\mathrm{st}}$ is mean value of this component for this strain (Tables 2, 4, or 6 ), and $M_{\text {CLA5A }}$ is the mean value of this component for wild-type strain CLA 5A (Tables 2, 4, or 6).

To calculate the relative value of latent period for each strain, the following equation was used: $R_{\mathrm{lp}}=D_{\mathrm{CLA} 5 \mathrm{~A}} / D_{\mathrm{st}}$, where $R_{\mathrm{lp}}$ is the relative value of latent period for a given strain and $D_{\mathrm{CLA} 5 \mathrm{~A}}$ is mean value of latent period in days for CLA 5A (Table 3).
$D_{\text {st }}$ is mean value of latent period for this strain (Table 4). With the equations above, the relative values of number of infections $\left(R_{\mathrm{ln}}\right)$, latent period $\left(R_{\mathrm{lp}}\right), \operatorname{LER}\left(R_{\mathrm{le}}\right)$, and sporulation $\left(R_{\mathrm{sp}}\right)$ for each strain in relation to those for CLA 5A were calculated (Table 7). We used the term INDEX to represent the overall fitness for each strain in relation to CLA 5A. INDEX was determined by the following equation: INDEX $=R_{\mathrm{ln}} \times R_{\mathrm{lp}} \times R_{\mathrm{le}} \times R_{\mathrm{sp}}$.

The wild-type strain, 3-1-3, had a higher value of INDEX than all mutant strains (Table 7). The order of overall fitness of mutant strains based on INDEX values was B21 > B18> B15> B13 for benomylresistant strains and Nit $R>$ Nit $T>N i t L$ $>$ Nit A for nitrate nonutilizing strains, respectively.

The method described above can be used to estimate overall fitness related to that of CLA 5A for any strain of C. gloeosporioides f. sp. aeschynomene, by means of component values. The results here are consistent with evidence for competitiveness of wild-type and mutant strains of $C$. gloeosporioides f. sp. aeschynomene previously studied in greenhouse experiments (27). Reduced fitness is usually related to changes in values for components such as fewer lesions, shorter infectious period, slower LER, and longer latent period $(14,15)$. Component analysis not only may provide the evidence for a pathogen's fitness on a plant such as northern jointvetch but also can provide predictive information on the population dynamics of strains in the field. Competition between $C$. gloeosporioides f. sp. aeschynomene strains and the consequences of the competition in terms of population changes may be better evaluated with parameters obtained from this study after additional research, including field tests and simulation modeling. However, to further estimate the competitiveness of any one strain of C. gloeosporioides f. sp. aeschynomene by disease components, additional questions must be answered. Changes in weather could significantly influence the expression and interactions of disease

Table 7. Computed relative values for infection components and index values for the 10 tested strains of Colletotrichum gloeosporiodes $\mathrm{f}$. sp. aeschynomene ${ }^{\mathrm{y}}$

\begin{tabular}{lccccc}
\hline Strain & $\mathbf{R}_{\mathbf{l n}}$ & $\mathbf{R}_{\mathbf{l p}}$ & $\mathbf{R}^{\mathbf{l e}}$ & $\mathbf{R}_{\mathbf{s p}}$ & INDEX $^{\mathbf{e}}$ \\
\hline 3-1-3 & 0.49 & 0.97 & 1.23 & 0.76 & 0.4443 \\
CLA 5A & 1.00 & 1.00 & 1.00 & 1.00 & 1.0000 \\
B13 & 0.87 & 0.87 & 0.10 & 0.27 & 0.0204 \\
B15 & 0.68 & 0.94 & 0.28 & 0.31 & 0.0555 \\
B18 & 0.98 & 0.87 & 0.22 & 0.45 & 0.0844 \\
B21 & 0.77 & 0.91 & 0.37 & 0.58 & 0.1503 \\
Nit A & 0.22 & 0.94 & 0.50 & 0.47 & 0.0007 \\
Nit L & 0.23 & 0.93 & 0.99 & 0.48 & 0.1016 \\
Nit R & 0.22 & 0.90 & 0.98 & 1.51 & 0.2930 \\
Nit T & 0.35 & 0.98 & 0.97 & 0.53 & 0.1763 \\
\hline
\end{tabular}

${ }^{y} R_{l n}, R_{l p}, R_{l e}$, and $R_{s p}$ are the relative values comparing the number of lesions, latent period, lesion expansion rate, and sporulation with values of CLA 5A, respectively. INDEX is calculated as follows: INDEX $=\mathrm{R}_{\mathrm{ln}} \times \mathrm{R}_{\mathrm{lp}} \times \mathrm{R}_{\mathrm{le}} \times \mathrm{R}_{\mathrm{sp}}$.

${ }^{\mathrm{z}}$ The calculated INDEX value describes the overall relative fitness of each strain in relation to the wild-type strain CLA 5A. components for individual strains. The interactions between temperatures during dew period, dew period duration, and incubation temperatures, and their effects on disease components, must be determined.

\section{LITERATURE CITED}

1. Antonovics, J., and Alexander, H. M. 1989 The concept of fitness in plant-fungal pathogen systems. Pages 185-214 in: Plant Disease Epidemiology: Population Dynamics and Management. K. J. Leonard and W. E. Fry, eds. McMillan Publishing, New York.

2. Ball, A. M., and Sidding, A. A. 1990. Assessment of benomyl resistance and mating type in field isolates of Pyrenopeziza brassicea, cause of light leaf spot of brassicas. Plant Pathol. 39:33-37.

3. Bowers, R.C. 1986. Commercialization of Collego $^{\mathrm{TM}}$ - An industrialist's view. Weed Sci. 34(Suppl.):24-25.

4. Correll, J. C., Klittich, C. J. R., and Leslie, J. F. 1987. Nitrate nonutilizing mutants of Fusarium oxysporum and their use in vegetative compatibility tests. Phytopathology 77:1640-1646.

5. Dovas, C., Skylakakis, G., and Georgopoulos, S G. 1976. The adaptability of benomyl-resistant population of Cercospora beticola in northern Greece. Phytopathology 66:1452-1456.

6. Hollins, T. W., Scott. P. R., and Paine, J. R. 1985. Morphology, benomyl resistance and pathogenicity to wheat and rye of isolates of Pseudocercosporella herpotrichoides. Plant Pathol. 34:369-379.

7. Holmstrom-Ruddick, B., and Mortenson, K. 1995. Factors affecting pathogenicity of a benomyl-resistant strain of Colletotrichum gloeosporioides f. sp. Malvae. Mycol. Res. 99:1108-1112.

8. Kadish, D., and Cohen, Y. 1988. Fitness of Phytophthora infestans isolates from metalaxyl-sensitive and -resistant populations. Phytopathology 78:912-915.

9. Lalancette, N., Hickey, K. D., and Cole, H., Jr 1987. Parasitic fitness and intrastrain diversity of benomyl-sensitive and benomyl-resistant subpopulations of Venturia inaequalis. Phytopathology 77:1600-1606.

10. Lenski, R. E. 1992. Relative fitness: Its estimation and its significance for environmental applications of microorganisms. Pages 183198 in: Microbial Ecology: Principles, Methods, and Applications. M. A. Levin, R. J. Seidler, and M. Rogul, eds. McGraw-Hill, New York.

11. Leonard, K. J., and Mundt, C. C. 1984. Methods for estimating epidemiological effects of quantitative resistance to plant diseases. Theor. Appl. Genet. 67: 219-230.

12. Luo, Y., and Zeng, S. M. 1995. Simulation studies on epidemics of wheat stripe rust (Puccinia striiformis) on slow-rusting cultivars and analysis of effects of resistance components. Plant Pathol. 44:340-349.

13. McGee, D. C., and Zuck, M. G. 1981. Competition between benomyl-resistant and sensitive strains of Venturia inaequalis on apple seedlings. Phytopathology 71:529-532.

14. Nelson, R. R. 1978. Genetics of horizontal resistance to plant diseases. Annu. Rev. Phytopathol. 16:359-78.

15. Parlevliet, J. E. 1979. Components of resistance that reduce the rate of epidemic development. Annu. Rev. Phytopathol. 17:203-222.

16. Ruppel, E. G. 1975. Biology of benomyltolerant strains of Cercospora beticola from sugar beet. Phytopathology 65:785-789.

17. Shabbi, E., Koenraadt, H., and Katan, T. 1986. Further studies of the inheritance of benomyl resistance in Venturia pirina isolated from pear orchards in Israel. Plant Pathol. 35: 310-313. 
18. Shaner, G. 1983. Growth of uredinia of Puccinia recondita in leaves of slow-and fastrusting wheat cultivars. Phytopathology 73: 931-935.

19. Shaner, G., and Hess, F. D. 1978. Equations for integrating components of slow leafrusting resistance in wheat. Phytopathology 68:1464-1469.

20. Spotts, R. A., and Cervantes, L. A. 1986. Populations, pathogenicity, and benomyl resistance of Botrytis spp., Penicillium spp., and Mucor piriformis in packinghouses. Plant Dis. 70:106-108.

21. TeBeest, D. O. 1982. Survival of Colletotrichum gloeosporioides $\mathrm{f}$. sp. aeschynomene in rice irrigation water and soil. Plant Dis. 66:
469-472.

22. TeBeest, D. O. 1984. Induction of tolerance to benomyl in Colletotrichum gloeosporioides $\mathrm{f}$. sp.. aeschynomene by ethyl methanesulfonate. (Abstr.) Phytopathology 74:864.

23. TeBeest, D. O. 1991. Ecology and epidemiology of fungal plant pathogens studied as biological control agents of weeds. Pages 97-114 in: Microbial Control of Weeds. D. O. TeBeest, ed. Chapman and Hall, New York.

24. TeBeest, D. O., Yang, X. B., and Cisar, C. 1992. The status of microbial control of weeds. Annu. Rev. Phytopathol. 31:547-567.

25. Yang, X. B., and TeBeest, D. O. 1992. Rain dispersal of Colletotrichum gloeosporioides under simulated rice field conditions. Phyto- pathology 82:1219-1222.

26. Yang, X. B., and TeBeest, D. O. 1992. Green treefrogs as vectors of Colletotrichum gloeosporioides. Plant Dis. 76:1266-1269.

27. Yang, X. B., and TeBeest, D. O. 1995. Competitiveness of mutant and wild-type isolates of Colletotrichum gloeosporioides f. sp. aeschynomene on northern jointvetch. Phytopathology 85:705-710.

28. Yang, X. B., TeBeest, D. O., and Smith, R. J., Jr. 1994. Distribution and grasshopper transmission of northern jointvetch anthracnose in rice. Plant Dis. 78:130-133.

29. Zadoks, J. C., and Schein, R. D. 1979. Epidemiology and Plant Disease Management. Oxford University Press, New York. 